\title{
A Compact Microstrip Spiral Antenna Embedded in Water Bolus for Hyperthermia Applications
}

\author{
Erdal Korkmaz, Omer Isik, and Mohammed Ahmed Nassor \\ Department of Electrical and Electronics Engineering, Fatih University, Istanbul 34500, Turkey \\ Correspondence should be addressed to Erdal Korkmaz; ekorkmaz@fatih.edu.tr
}

Received 20 December 2012; Revised 7 March 2013; Accepted 17 March 2013

Academic Editor: P. Mohanan

Copyright (C) 2013 Erdal Korkmaz et al. This is an open access article distributed under the Creative Commons Attribution License, which permits unrestricted use, distribution, and reproduction in any medium, provided the original work is properly cited.

\begin{abstract}
This paper presents the design, simulation, fabrication, and measurement of a circular spiral microstrip antenna embedded in distilled water bolus. The antenna is mainly designed to operate at $434 \mathrm{MHz}$ ISM band to be used for a hyperthermia applicator. The performance of the antenna is compared to a conventional patch antenna also embedded in water bolus. The results show that spiral antenna has significant narrower radiation pattern and is capable to operate at multiple frequencies as well. Narrow beam of the antenna is desired to design a multiantenna arrangement with less coupling and a better focusing resolution which can be crucial for deep regional hyperthermia applications. The option of other frequencies is desirable to have a better control over the penetration depth versus focusing depending on the application region.
\end{abstract}

\section{Introduction}

In electromagnetic hyperthermia method, the tissues are exposed to electromagnetic radiation externally to increase the temperature to around $42^{\circ} \mathrm{C}$. It is well known that at these temperatures, the cancerous cells ruin the cells protein build, change the cell construction, and even kill them $[1,2]$. The basic parameter to increase the temperature in the tissues is the electromagnetic field power absorption described by specific absorption ratio (SAR). A temperature elevation in cancerous region leads to an increase in blood circulation rate and hence hyperthermia can also be used in conjunction with conventional therapies such as chemotherapy and radiation therapy $[3,4]$. As a result of a faster blood circulation, the perfusion rate increases and the cancer drugs penetrates better into tumor, or a denser oxygenation makes cancer cells more sensitive for ionized radiation.

Several applicators have been developed for noninvasive local and regional hyperthermia applications [5-11]. Usually superficial hyperthermia applicators use single relatively big antennas (local hyperthermia), whereas for deep located tumors, a multiantenna system is used (regional hyperthermia). In a multiantenna system, the constructive interference of the fields on the targeted region is intended since the electromagnetic penetration decreases rapidly through the lossy character of the tissues. Hence, the design of an effective single antenna element is the crucial step in the development of a specific applicator. When designing the single antenna element, a tradeoff must be found between the penetration depth (lower frequency) and resolution (higher frequency). In order to develop a multiantenna applicator, there is a need for directive antennas operating at relatively lower frequencies (preferable ISM bands), having smaller lateral size and narrower beam width. However, the inverse relationship between the electrical sizes of the antennas and their operating frequency constraints the design of such antennas.

The design of a hyperthermia antenna significantly differs from the antenna designs in free space applications. In hyperthermia applicators usually the antennas are embedded in distilled water bolus to obtain a better coupling of the irradiated electromagnetic fields with the tissues $[9,10,12-$ 17]. In addition, the water bolus serves also for the cooling of possible superficial heating and reduces the size of the designed antenna with respect to the resonant frequency.

The aim of this study is to design a directive antenna at $434 \mathrm{MHz}$ (ISM frequency band) to be used in a hyperthermia applicator. To that end, microstrip antenna is chosen as a template since it has a high performance in many applications due to its lightweight, low profile with conformability, and 


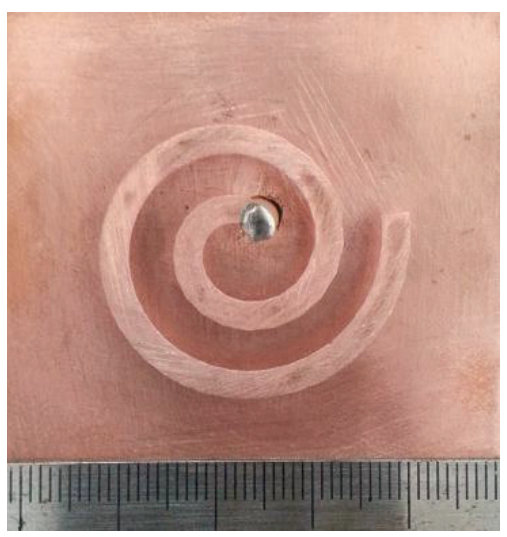

(a)

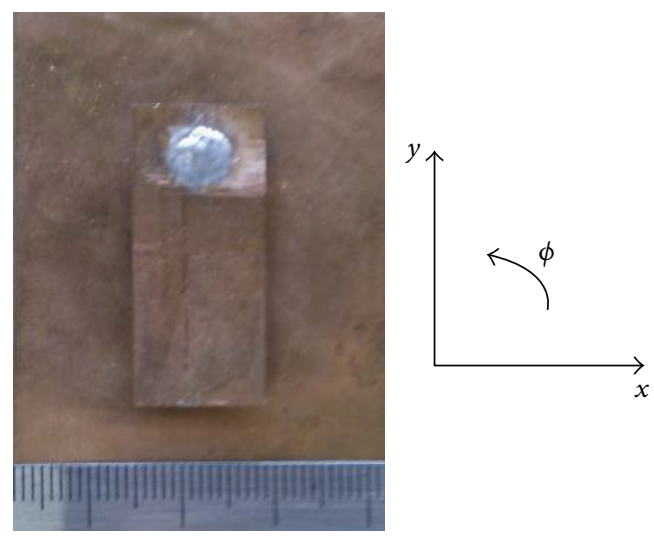

(b)

Figure 1: Top view of the spiral (a) and patch (b) antennas.

ease of integration in other systems [18]. Typical microstrip antenna designs use a solid substrate with a dielectric constant $\varepsilon_{r}<15$. The design of a microstrip antenna with solid substrate requires relatively huge lateral size of the antenna which makes the antenna not suitable for a multiantenna applicator. If a water bolus is placed between the antenna and the targeted body, then most of the energy will be reflected at the antenna-water interface and as a result most of the radiation will be in the lateral direction which is strictly an unwanted situation. However, if distilled water is used as a substrate or practically if the antenna is embedded in a water bolus, then that will result in a considerable reduction of the antenna size with respect to its resonant frequency due to a higher dielectric constant. The water bolus will not only serve for cooling of the skin and superficial tissues but also serve for the cooling of antenna to sustain stable antenna characteristics during the treatment [19].

In this work, we present the design and analysis of a circularly spiral shaped microstrip antenna embedded in a water bolus. The proposed spiral antenna is intended to be used as the single antenna element in a possible cancerspecific deep regional hyperthermia applicator in the future.

\section{Antenna Structure}

For the design of a hyperthermia antenna, many antenna structures are studied [19-25]. The aim of this study was to design an antenna to be suitable in a multi antenna applicator for semideep or deep located tumors with the following specifications. The resonance frequency should be at $434 \mathrm{MHz}$ (preferably resonating in multiple frequencies as well as in case of penetration depth and resolution tradeoff), having a radiation pattern as narrow as possible to reduce the coupling between the antennas and having a lateral size as small as possible. To that end, a planar microstrip spiral antenna submerged in a deionized water bolus has been designed.

The antenna dimensions are optimized to obtain the best performance relevant to the prescribed aims. The top view of the realized spiral antenna is shown in Figure 1. The antenna consists of a PEC ground plane, the spiral has two turns, the width of the microstrip is $3.25 \mathrm{~mm}$, the gap between the turns is $3.55 \mathrm{~mm}$, and the height from the antenna to the ground is $3.6 \mathrm{~mm}$. The antenna is fed by an SMA connector, and the inner pin of the connector that has a diameter of $1.27 \mathrm{~mm}$ is soldered to the center of the spiral antenna. The microstrip thickness is chosen as $0.3 \mathrm{~mm}$ to have a rigid construction since the only solid support is the inner pin. The ground has a dimension of $4.5 \mathrm{~cm}$ by $4.5 \mathrm{~cm}$. The material properties of the deionized water at $434 \mathrm{MHz}$ and room temperature are $\varepsilon_{r}=78.4$, and the electrical conductivity $\sigma=5.55 \mu \mathrm{S} / \mathrm{m}$. The antenna operates only inside a deionized water bolus, in other words, both the substrate and the background environment of the antenna is deionized water. In an applicator design, the water will circulate the skin to cool the possible superficial heating as well as to cool the antenna itself at high powers.

Since one of the aims of this study is to design an antenna with a narrower radiation beam, the actual radiation pattern of the antenna is concerned. To that end, we designed a conventional rectangular patch antenna inspired from [19] resonating at $434 \mathrm{MHz}$ and used it as the probe for the measurements. The patch antenna dimensions are also optimized to obtain the best performance relevant to the prescribed aims. That gives also the opportunity to compare the conventional patch antenna with the proposed spiral antenna. The designed antenna has a PEC ground plane, the patch length is $32.64 \mathrm{~mm}$, width is $14 \mathrm{~mm}$, height from the ground plane is $3.6 \mathrm{~mm}$, and the feeding point is $4.75 \mathrm{~mm}$ from the patch's longitudinal direction. The ground has a dimension of $4 \mathrm{~cm}$ by $5 \mathrm{~cm}$. The thickness of the patch is $0.5 \mathrm{~mm}$, and the only support of the patch is the inner pin of the SMA connector. The antenna is also embedded in deionized water.

\section{Simulation and Measurement Results}

Both the design and simulation of the antennas are performed by means of a commercial electromagnetic simulation software which uses finite integration technique in time domain as a solver. The main parameters which are influencing the resonating frequency are the width of the microstrip and 


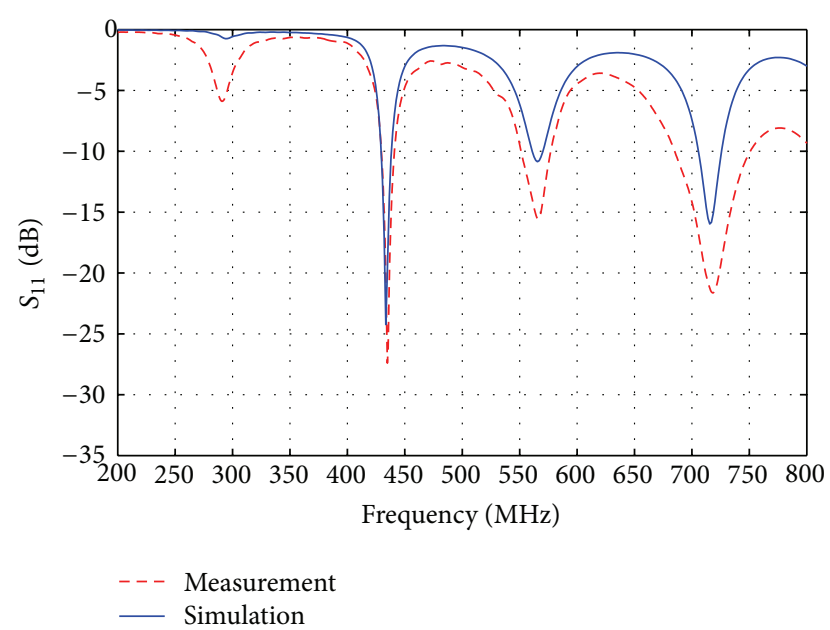

Figure 2: Simulation (solid line) and measurement (dashed line) $\mathrm{S}_{11}$ values for spiral antenna.

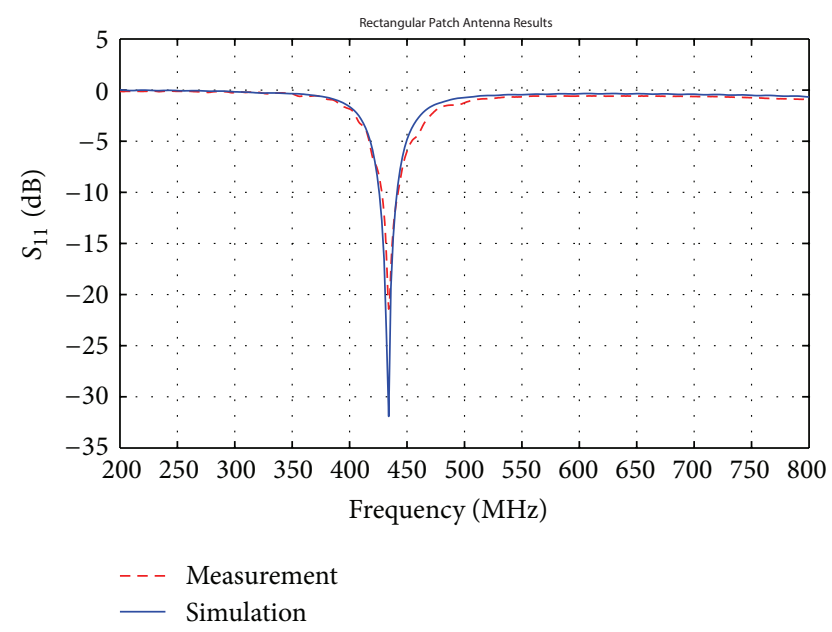

Figure 3: Simulation (solid line) and measurement (dashed line) $\mathrm{S}_{11}$ values for patch antenna.

the gap between the strips. Keeping the overall size constant, we obtained for different ratios of these two parameters the similar resonating frequencies, whereas at the proposed ratios, the beam width is the narrowest. For the measurements, a vector network analyzer of Anritsu VectorStar MS4642A is used. The simulated and measured return loss values inside a water bolus for the spiral are depicted in Figure 2 and for the patch are depicted in Figure 3. A very good agreement has been obtained between the measured and simulated results both for the spiral and patch antenna; nevertheless, the software underestimates the performance of spiral antenna slightly for 566 and $716 \mathrm{MHz}$ frequencies.

To conduct the radiation pattern measurements, we filled a circular basin with deionized water and constructed a measurement setup as depicted in Figure 4 . The wavelength at $434 \mathrm{MHz}$ inside the deionized water is $\lambda=\lambda_{0} / \sqrt{\varepsilon_{r}}=$ $78 \mathrm{~mm}$, where $\lambda_{0}$ is the free space wavelength. Taking into account the far-field formula, the required minimum distance

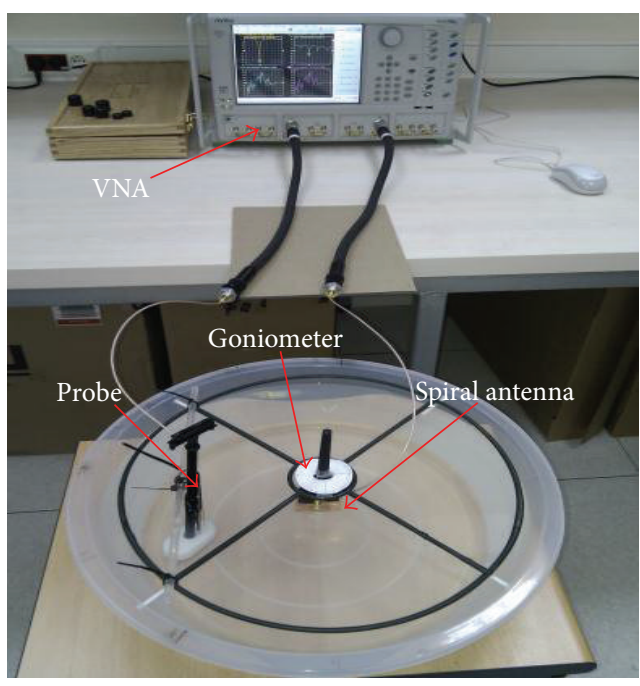

FIGURE 4: Measurement setup for manual radiation pattern measurements.

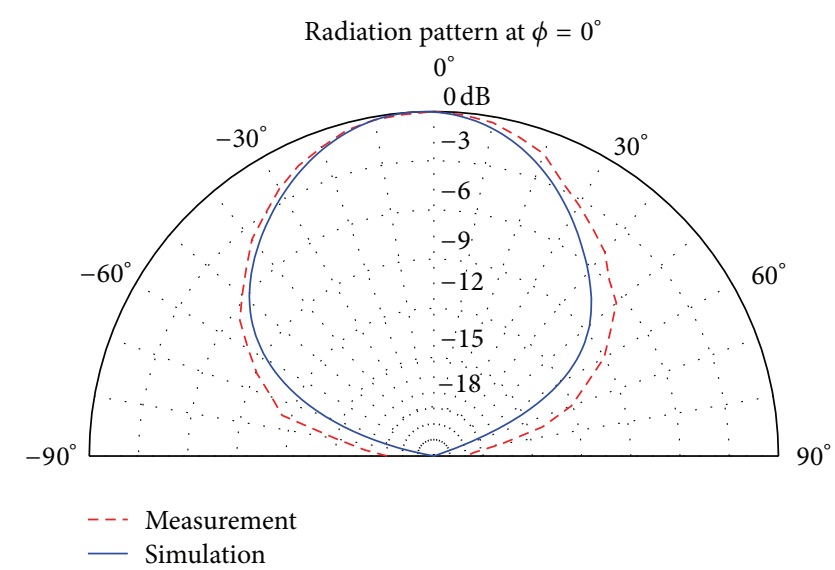

(a)

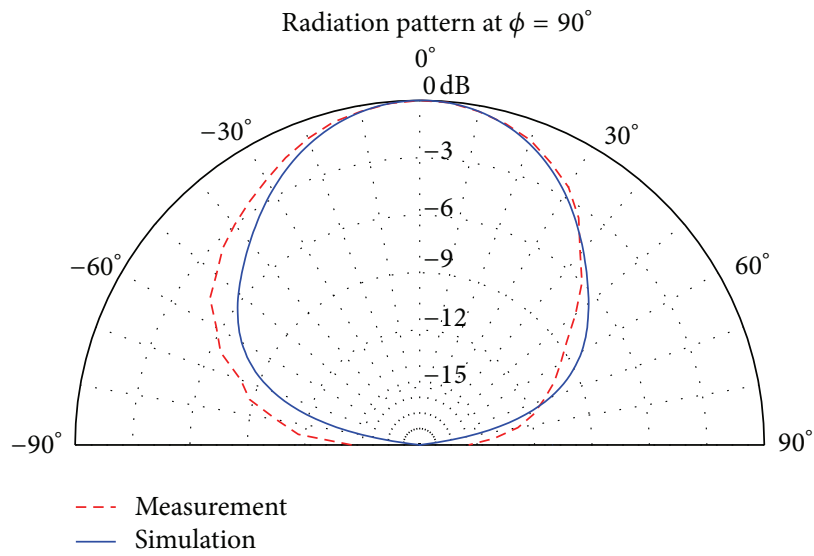

(b)

Figure 5: Simulated (solid line) and measured (dashed line) radiation patterns of spiral antenna at $434 \mathrm{MHz}$, for $\phi=0$ plane (a) and $\phi=90^{\circ}$ plane (b). 


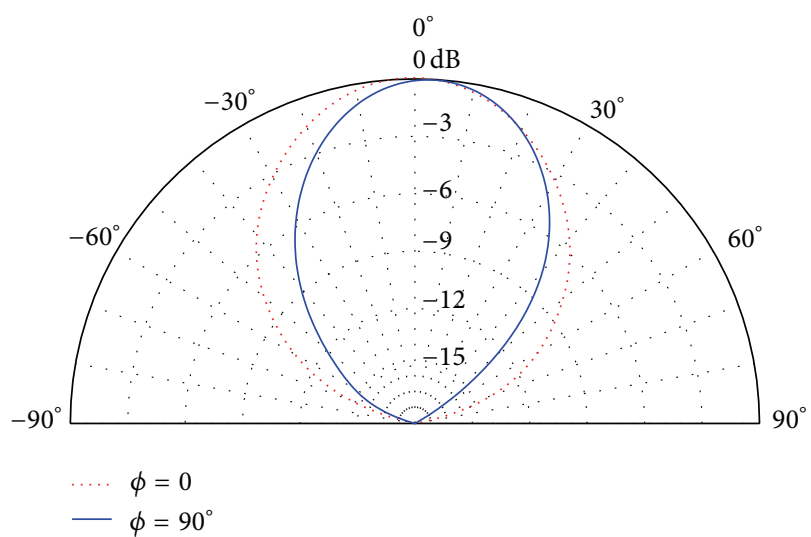

(a)

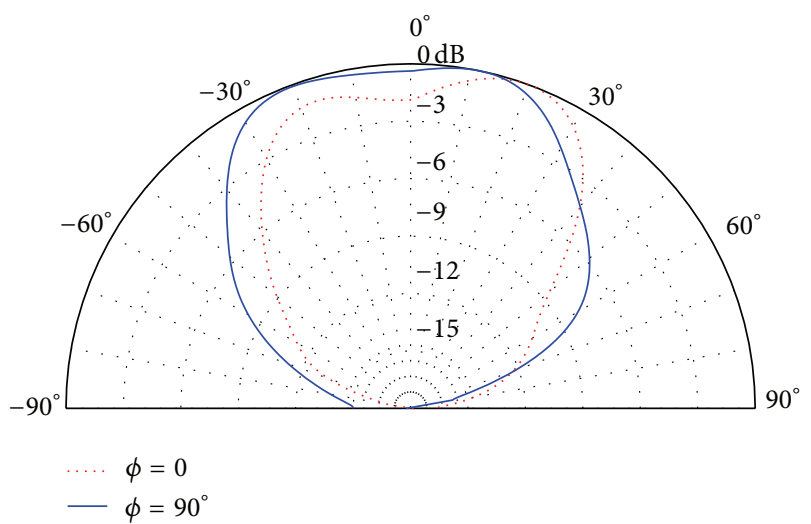

(b)

FIgURE 6: Simulated radiation patterns of spiral antenna at $566 \mathrm{MHz}$ (a) and at $716 \mathrm{MHz}$ (b).

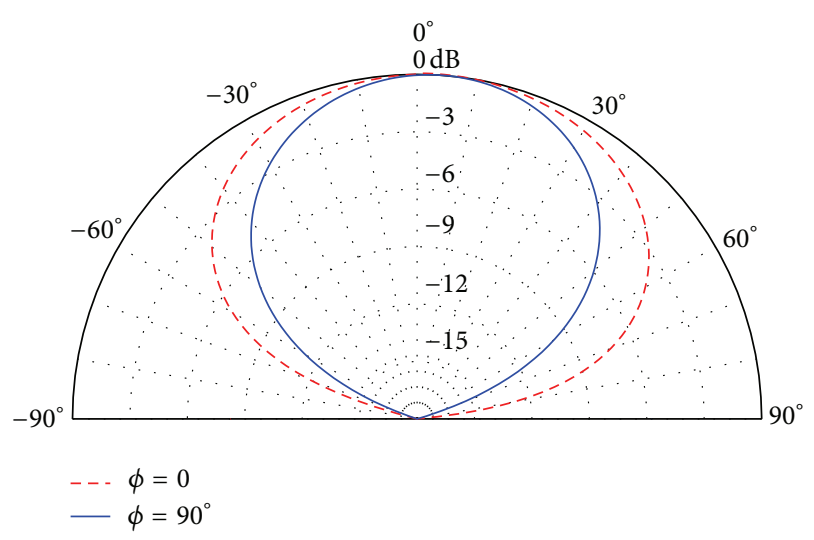

FIGURE 7: Simulated radiation patterns of patch antenna at $434 \mathrm{MHz}$.

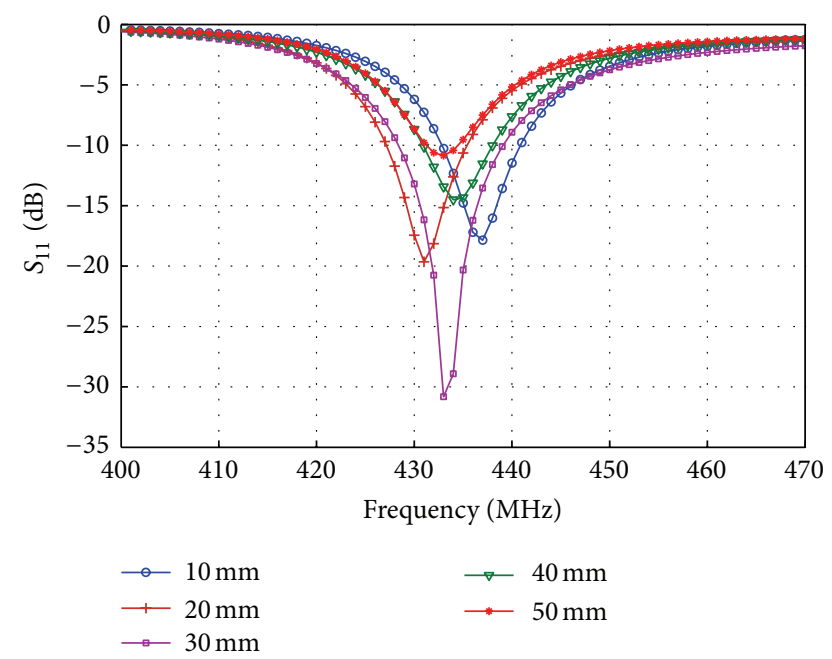

FIGURE 8: $S_{11}$ values for spiral antenna at a different water bolus height. is $d=2 D^{2} / \lambda \approx 25 \mathrm{~mm}$. Hence, a distance about $15 \mathrm{~cm}$ in the measurement setup is set between the antennas. The spiral antenna is mounted to a rod and positioned at the middle of the basin and rotated manually by $5^{\circ}$ steps. We used two additional low loss coax cables as an extension to the expensive calibration cables for the connection of the antennas in water and did perform the calibration taking into account the extended parts. We also used the time domain option of VNA to reduce the environmental noise. The comparison between the simulation and measurement results is depicted in Figure 5. Despite not having an ideal radiation pattern measurement setup like an anechoic chamber in free space measurements, a good agreement is obtained. The small discrepancies in the measured results are probable mainly due to the manual rotation of the antenna. The half power beam width (HPBW) of the spiral antenna is smaller than $65^{\circ}$ for each plane. Another reason to choose a spiral antenna is that it resonates at multiple frequencies. The radiation pattern of spiral antenna at $566 \mathrm{MHz}$ is even narrower than at $434 \mathrm{MHz}$ while at $716 \mathrm{MHz}$ some distortion occurs (Figure 6). The simulated radiation pattern of the patch antenna is depicted in Figure 7. The HPBW for the patch antenna is $75^{\circ}$ at $\phi=0$ plane and $107^{\circ}$ at $\phi=90^{\circ}$ plane. These values are significantly greater than the spiral antenna results. The polarization of the spiral antenna shown in Figure 1 has right-hand circular polarization (actually slightly elliptical) observed through simulations.

In case of designing an applicator, the robustness of the single antenna element is important. However, in our design the antenna does not have a solid substrate and the only support is that the inner pin of the connector makes the antenna vulnerable. As a remedy, for example, at three points, small thin plastic pins are fixed as a support between the spiral and the ground. A slight shift in the operating frequency is observed both in the measurements and simulations. Fortunately, that shift can easily be taken into account by including the support pins in the design to set the operation at the desired frequency. In addition, the spiral antenna has 


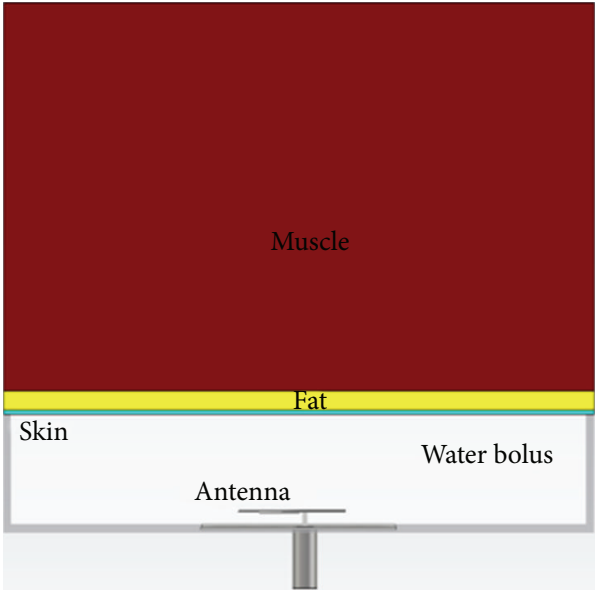

(a)

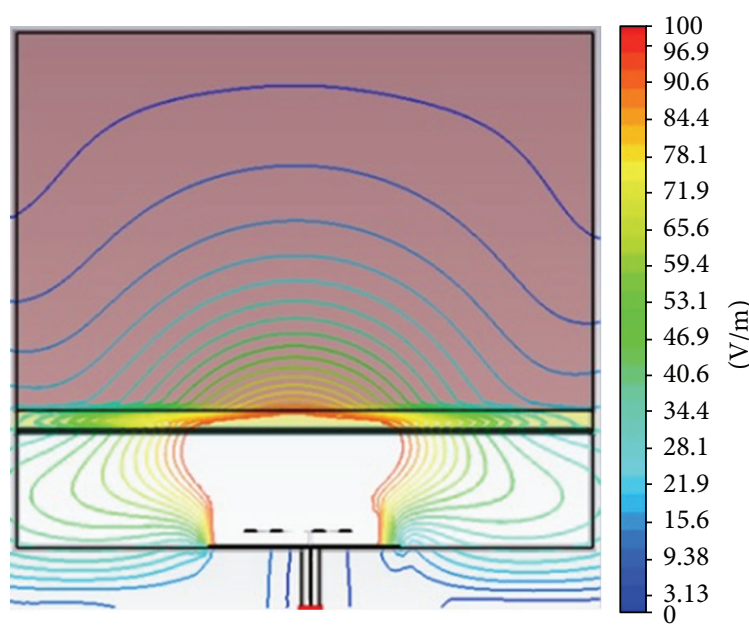

(b)

Figure 9: Spiral antenna model inside a water bolus $(3 \mathrm{~cm})$ with tissues of skin, fat, and muscle (a) and the electric field lines at $434 \mathrm{MHz}(\mathrm{b})$.

a realized gain of $9.7 \mathrm{~dB}$ and the radiation efficiency is about $-0.0074 \mathrm{~dB}$ from the simulation results.

In order to investigate the performance of the antenna in presence of tissues, we performed simulations with a simplistic homogeneous model of $15 \mathrm{~cm} \times 15 \mathrm{~cm}$ area with a thickness of a $1 \mathrm{~mm}$ skin, $5 \mathrm{~mm}$ fat, and $100 \mathrm{~mm}$ muscle, taking into account the material properties at $434 \mathrm{MHz}$. The antenna should be located as close as possible to the skin in order to transfer maximum power while the antenna characteristics should remain unaltered. The $S_{11}$ parameters of the spiral antenna with altering the water bolus thickness between 10 and $50 \mathrm{~mm}$ are depicted in Figure 8. Results show that the antenna reflection coefficient values are slightly shifted for $10-20 \mathrm{~mm}$, and at $30 \mathrm{~mm}$ the optimum distance is obtained. This is perceptible since the minimum far-field distance is about $25 \mathrm{~mm}$. In addition we put electric field monitors at the axial cross-section of the antenna to monitor the radiation behavior into the tissues. The electric field lines at $30 \mathrm{~mm}$ water bolus thickness are depicted in Figure 9. We observed a similar radiation behavior (at other water bolus thicknesses as well as other cross-sections) as that in water bolus without the tissues both for the spiral and patch antennas. The narrow radiation beam of the spiral antenna into the tissues apparently shows the adequateness of the single antenna element for a possible applicator design.

Considering the antenna designs in the literature [1824], the focus of the studies is to heat the whole region instead of a focused smaller region. The reason for that is to use the applicator in conjunction with conventional methods like chemo- and radiotherapy and to reduce the uncertainty in the imaging of the infected region. That is why in their designs, the narrow radiation beam was not preferred. Fortunately, the advancement in the imaging technology and the hardware and software capabilities of the electromagnetic simulation tools promise now to focus the heat on a smaller region.

\section{Conclusion}

This paper proposes a compact novel circular microstrip spiral antenna with a narrower radiation pattern which can be considered as an adequate choice to be used in a multi antenna applicator for semideep or deep hyperthermia applications. The narrow radiation pattern and small size are desirable characteristics to place more antennas in an (circular) array configuration and to reduce the constructive interference at superficial regions to obtain a better focusing at the targeted region. The operation at multifrequencies can be used in case of penetration depth and focusing considerations. A firm construction can be obtained using small thin support pins.

\section{Acknowledgment}

This work was supported by The Scientific and Technological Research Council of Turkey (TUBITAK) under Project no. 111E087.

\section{References}

[1] J. van der Zee, "Heating the patient: a promising approach?" Annals of Oncology, vol. 13, no. 8, pp. 1173-1184, 2002.

[2] B. Hildebrandt, P. Wust, O. Ahlers et al., "The cellular and molecular basis of hyperthermia," Critical Reviews in Oncology/Hematology, vol. 43, no. 1, pp. 33-56, 2002.

[3] P. Wust, B. Hildebrandt, G. Sreenivasa et al., "Hyperthermia in combined treatment of cancer," Lancet Oncology, vol. 3, no. 8, pp. 487-497, 2002.

[4] M. H. Falk and R. D. Issels, "Hyperthermia in oncology," International Journal of Hyperthermia, vol. 17, no. 1, pp. 1-18, 2001.

[5] I. J. Bahl, S. S. Stuchly, J. W. Lagendijk, and A. M. Stuchly, "Microstrip loop radiators for local hyperthermia," in Proceedings of the IEEE EEE/MTT-S International Microwave Symposium, pp. 465-467, Los Angeles, Calif, USA, June 1981. 
[6] W. Gee, S. W. Lee, N. K. Bong, C. A. Cain, R. Mittra, and R. L. Magin, "Focused array hyperthermia applicator: theory and experiment," IEEE Transactions on Biomedical Engineering, vol. 31, pp. 38-46, 1984.

[7] Y. Nikawa, H. Watanabe, M. Kikuchi, and S. Mori, "A directcontact microwave lens applicator with a microcomputercontrolled heating system for local hyperthermia," IEEE Transactions on Microwave Theory and Techniques, vol. 34, no. 5, pp. 626-630, 1986.

[8] M. D. Sherar, F. F. Liu, D. J. Newcombe et al., "Beam shaping for microwave waveguide hyperthermia applicators," International Journal of Radiation Oncology, Biology, Physics, vol. 25, no. 5, pp. 849-857, 1993.

[9] R. C. Gupta and S. P. Singh, "Development and analysis of a microwave direct contact water-loaded box-horn applicator for therapeutic heating of bio-medium," Progress in Electromagnetics Research, vol. 62, pp. 217-235, 2006.

[10] M. M. Paulides, J. F. Bakker, E. Neufeld et al., "The HYPERcollar: a novel for hyperthermia in the head and neck," International Journal of Hyperthermia, vol. 23, no. 7, pp. 567-576, 2007.

[11] C. J. Trujillo, L. Leija, and A. Vera, "Design and preliminary evaluation of a superficial applicator for hyperthermia with a new coaxially fed antenna: theoretical models," in Proceedings of the Pan American Health Care Exchanges, pp. 62-67, Lima, Peru, March 2010.

[12] M. A. Ebrahimi-Ganjeh and A. R. Attari, "Study of water bolus effect on SAR penetration depth and effective field size for local hyperthermia," Progress In Electromagnetics Research B, vol. 4, pp. 273-283, 2008.

[13] E. Korkmaz, M. A. Nassor, S. Kara, O. Isik, and B. Turetken, "Design of compact microstrip antennas embedded in water bolus for hyperthermia applications," in Proceedings of the IEEE International Symposium on Antennas and Propagation, Chicago, Ill, USA, 2012.

[14] T. Juang, D. Neuman, J. Schlorff, and P. R. Stauffer, "Construction of a conformal water bolus vest applicator for hyperthermia treatment of superficial skin cancer," IEEE Engineering in Medicine and Biology Society, vol. 2, pp. 3467-3470, 2004.

[15] D. G. Neuman, P. R. Stauffer, S. Jacobsen, and F. Rossetto, "SAR pattern perturbations from resonance effects in water bolus layers used with superficial microwave hyperthermia applicators," International Journal of Hyperthermia, vol. 18, no. 3, pp. 180-193, 2002.

[16] R. C. Gupta and S. P. Singh, "Analysis of the SAR distributions in three-layered bio-media in direct contact with a waterloaded modified box-horn applicator," IEEE Transactions on Microwave Theory and Techniques, vol. 53, no. 9, pp. 2665-2671, 2005.

[17] S. Jacobsen and P. R. Stauffer, "Multifrequency radiometric determination of temperature profiles in a lossy homogeneous phantom using a dual-mode antenna with integral water bolus," IEEE Transactions on Microwave Theory and Techniques, vol. 50, no. 7, pp. 1737-1746, 2002.

[18] R. Garg, P. Bhartia, I. Bahl, and A. Ittipiboon, Microstip Antenna Design Handbook, Artech, Norwwod, Mass, USA, 2001.

[19] M. M. Paulides, J. F. Bakker, N. Chavannes, and G. C. Van Rhoon, "A patch antenna design for application in a phasedarray head and neck hyperthermia applicator," IEEE Transactions on Biomedical Engineering, vol. 54, no. 11, pp. 2057-2063, 2007.

[20] S. Curto, P. McEvoy, X. Bao, and M. J. Ammann, "Compact patch antenna for electromagnetic interaction with human tissue at $434 \mathrm{MHz}$," IEEE Transactions on Antennas and Propagation, vol. 57, no. 9, pp. 2564-2571, 2009.

[21] I. J. Bahl, S. S. Stuchly, J. W. Lagendijk, and M. A. Stuchly, "Microstrip loop radiators for local hyperthermia," in IEEE MTT-S International Microwave Symposium Digest, pp. 465467, June 1981.

[22] D. Andreuccetti, M. Bini, A. Ignesti, R. Olmi, S. Priori, and R. Vanni, "High permittivity patch radiator for single and multi-element hyperthermia applicators," IEEE Transactions on Biomedical Engineering, vol. 40, no. 7, pp. 711-715, 1993.

[23] S. Jacobsen, H. O. Rolfsnes, and P. R. Stauffer, "Characteristics of microstrip muscle-loaded single-arm Archimedean spiral antennas as investigated by FDTD numerical computations," IEEE Transactions on Biomedical Engineering, vol. 52, no. 2, pp. 321-330, 2005.

[24] W. T. Chen and H. R. Chuang, "Numerical computation of the EM coupling between a circular loop antenna and a full-scale human-body model," IEEE Transactions on Microwave Theory and Techniques, vol. 46, no. 10, part 1, pp. 1516-1520, 1998.

[25] S. Curto and M. J. Ammann, "Electromagnetic interaction between resonant loop antenna and simulated biological tissue," Microwave and Optical Technology Letters, vol. 48, no. 12, pp. 2418-2421, 2006. 

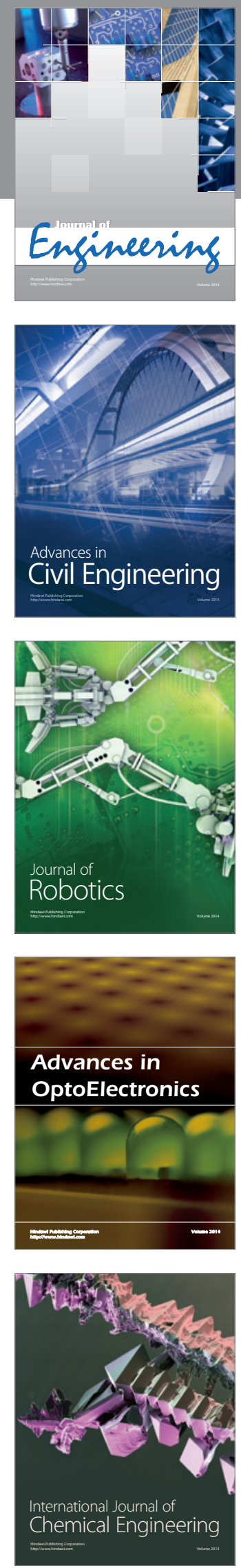

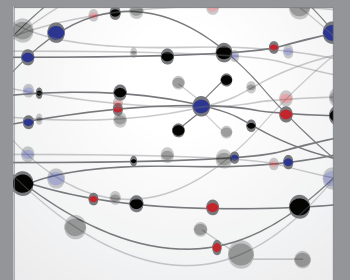

The Scientific World Journal
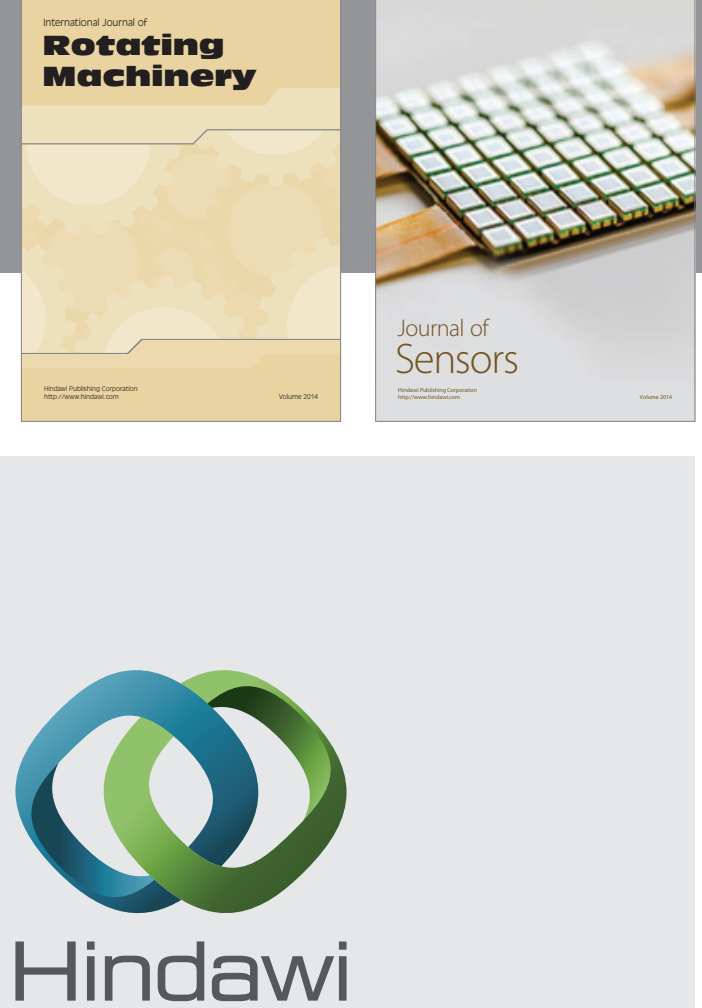

Submit your manuscripts at http://www.hindawi.com
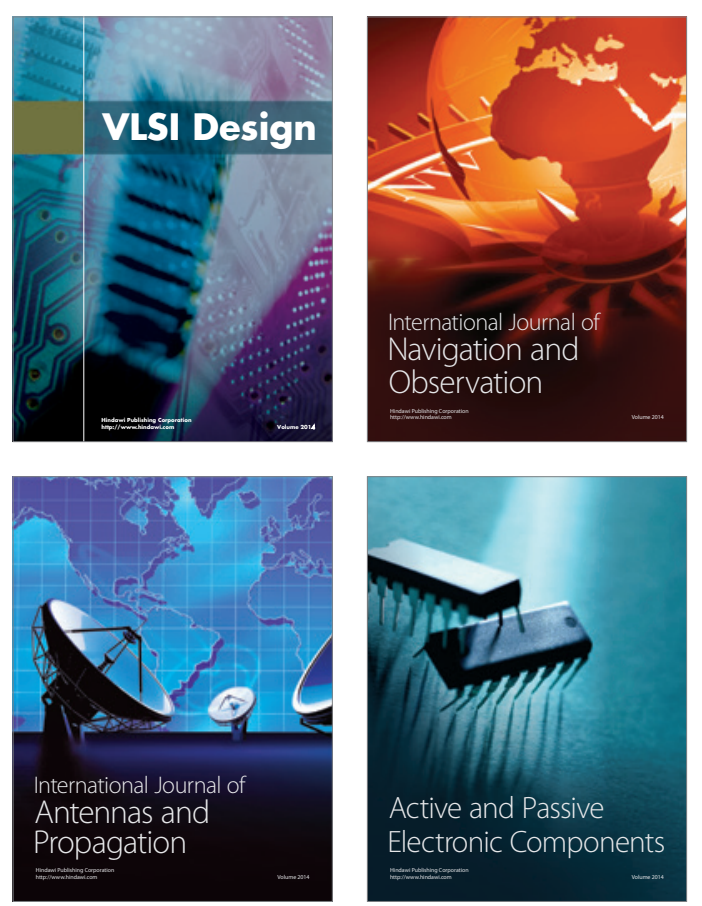
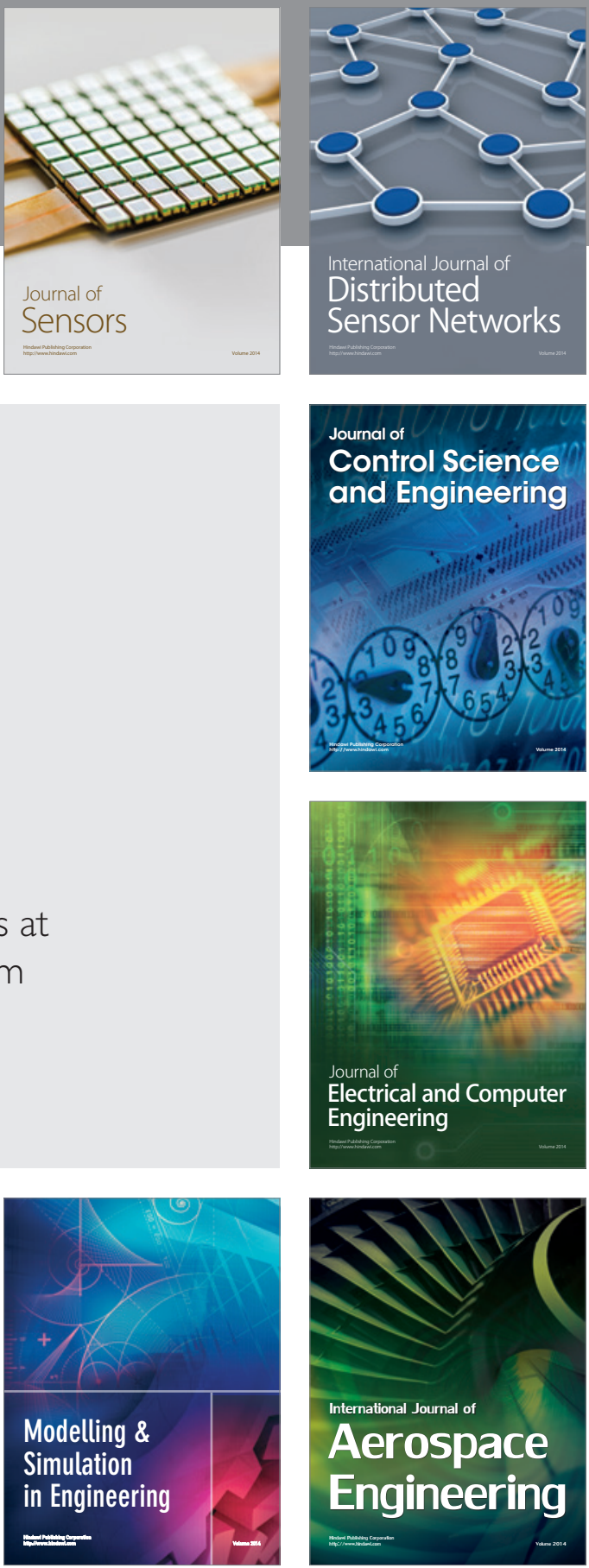

Journal of

Control Science

and Engineering
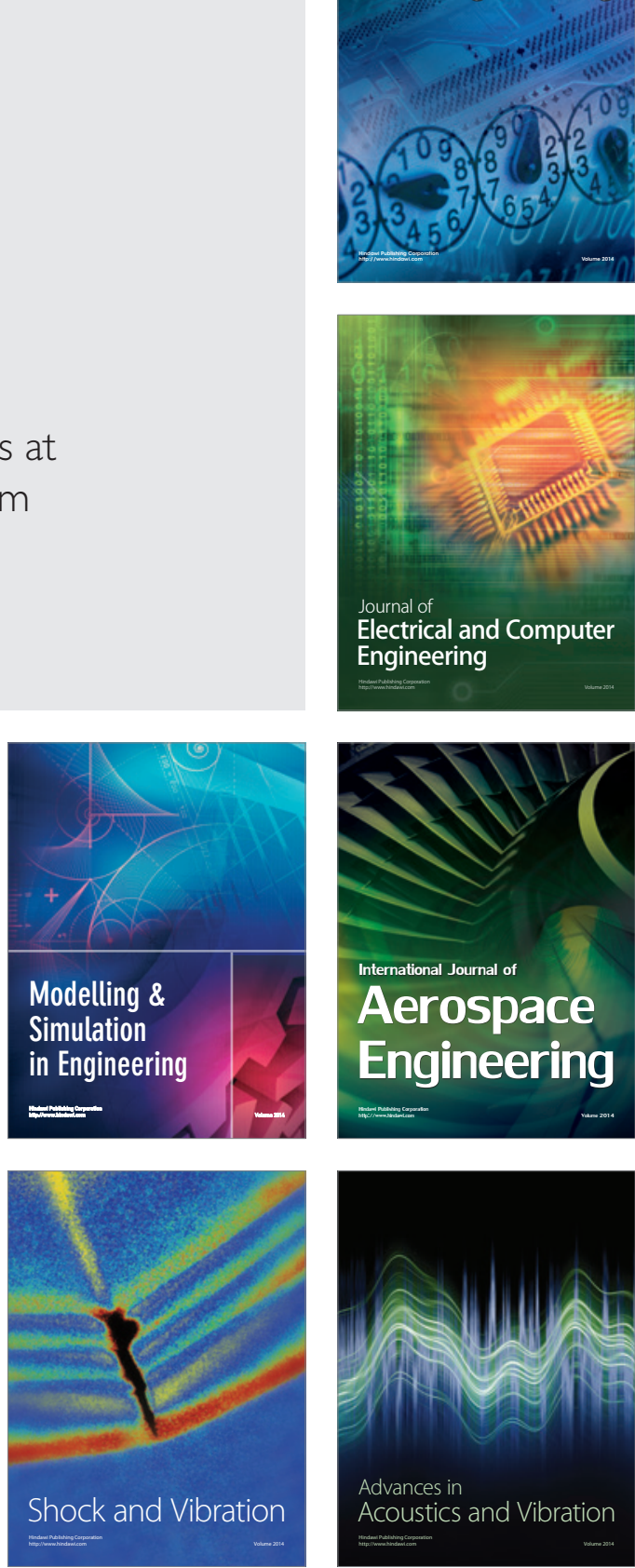